share knowledge, tools and techniques for improving care for residents.

Using the impetus of "Dying Matters" week in May 2016, the Devon Care Home Kitemark group have now established a plan for a peer-review pilot of End of Life Care in their homes.

The initial pilot visits will be undertaken in Summer 2016, with a view to developing a process to be used across all 60 sites.

Methods included will be:

- Site visits undertaken by peers, with the support of the local specialist palliative care team where appropriate.

- Completion of peer review feedback sheets to clarify strengths and challenges for each home.

- The process will be developed and refined over time, according to feedback from staff, residents and managers.

Rather than using existing models of teaching and training in care homes (eg. Six Steps, GSF for Care Homes), which have to date been led by "experts", this work has uniquely been driven by care homes themselves. The aim is that homes will be able to make quality improvements in a meaningful, sustainable way.

By looking carefully at generic challenges for the Kitemark Homes in the local area, a further key aim will be to identify how to improve End of Life care across boundaries for our care home residents.

\section{P-161 ABSTRACT WITHDRAWN}

\section{P-162 CHAMPIONING SPECIALIST CARE AT HOME IN EVERYDAY DYING}

Nicola Woodyatt, Sridevi Singh. Macmillan Cancer Support, London, UK

\subsection{6/bmjspcare-2016-001245.184}

The cancer story is changing, by 2020, almost one in two people will get cancer and $47 \%$ of those who died that year will have had cancer. We are reminded that choice at the end of life is so important and Macmillan wants everyone to have more choice.

This session looks at the Macmillan Specialist care at Home partnership approach to providing palliative care to people in the community. It's based on the successful model developed in Midhurst where people experienced less frequent $\mathrm{A}$ and $\mathrm{E}$ attendances, decreased hospital stays and a majority of people died in their preferred place. Macmillan have since identified and supported six innovation centres that have adopted this model.

Each centre has adopted the model of person-centred care, which emphasises principles such as having a consultant led multidisciplinary team - doctors, nurses, clinical nurse specialist, occupational therapist, physiotherapists and counsellors; flexible teamwork between specialists, generalists and trained volunteers in the community. This has enabled timely referral, home-based clinical interventions and close, flexible collaboration between primary care and other community-based services. Each centre is working in partnership with many different partners such as commissioners of end of life care, community/hospital providers and hospices.

The philosophy that makes the Macmillan Specialist Care at Home approach so successful is to ensure that the person and their families feel well supported and they receive personalised, coordinated care and this session will showcase some of the findings of this project.

\section{SO FAR}

${ }^{1}$ Karen Taylor, ${ }^{1,2}$ Simone Ali, ${ }^{2}$ Mags Bunting. ${ }^{1}$ Martlets Hospice, Hove, UK; ${ }^{2}$ Sussex Community NHS Foundation Trust

10.1136/bmjspcare-2016-001245.185

Introduction In April 2013 the Palliative Care Partnership, a collaboration between a NHS Community Palliative Care Team and a charitable Hospice at Home service was commissioned to provide community palliative/end of life care for patients in the local area.

Aims of service Improve outcomes for all patients locally with palliative/end of life care needs, regardless of diagnosis

Improve patient and carer experience

Maximise use of existing resources by reducing duplication and optimising efficiency: "right care, right time, right place".

Methods More joined-up approach to care/support achieved by:

- Single point of access $24 / 7$ via telephone hub, manned by NHS and hospice staff

- Joint triage system

- 7 day week visiting service

- Shared electronic patient record system

- Joint multidisciplinary meetings

- Joint governance framework

- Collaboration with other services.

Results Successes:

- Key Performance Indicators (KPIs) met/exceeded

- Reduction in inappropriate hospital admissions (>10/month, a saving of at least $£ 200,000$ /annum to local health economy)

- Dying in Preferred Place of Care increased to 89\%

- Telephone hub activity increased by over $50 \%$ out of hours

- $64 \%$ increase in first year in number of referrals with highly complex needs

- Carer feedback shows $83 \%$ received help as often as they needed

- Excellent feedback from local services

- Rating of "Outstanding" for responsiveness in Trust's latest CQC inspection.

Challenges:

- Demand on telephone hub soon exceeded capacity. Given the cost effectiveness of the service and impact on outcomes, additional resource was awarded by the commissioners

- Merging two organisations with different cultures, funding arrangements and systems. The common goal of high quality patient-centred care helped to overcome these challenges

- Data collection has been time consuming. We are currently refining our processes.

Conclusions Partnership working can significantly benefit patients and carers and be cost effective. KPIs need to be reviewed regularly to drive further improvement. Data collection and audit are key for service development.

\section{P-164 VOLUNTEERS AT LIFE'S END - VALE - IN THE COMMUNITY}

Andrew Lowden, Sheila Markham. LOROS, Leicester, UK

10.1136/bmjspcare-2016-001245.186 
The End of Life Care strategy promotes choice of place of care and of death for all patients, yet research continues to show more people die in hospital than anywhere else, despite home being the place of choice for the majority. (ONS 2014). Individuals who have no partner or family support, and are over 75 have almost no chance of achieving this goal (Gao et al., 2013).

A one-year pilot project, funded by St. James's Place Foundation planned, recruited, and trained volunteers with a health care background to be companions to lone patients who wanted to die at home. They offered sessions of around four hours duration to patients referred by primary care teams and who fulfilled agreed criteria. Volunteers were mainly available during evenings and at weekends, when most services are at their least wellstaffed. They offered a calm, reassuring and supportive presence to the patient and any family present.

Achieving choice of place of death for this specific patient group and deflecting inappropriate admissions were initial objectives. However, poor uptake resulted in wider geographic location, and extension of the service to patients in community hospitals and the hospice, and earlier, additional support, including to families.

Focus on this specific patient group is recommended as a national strategic objective, to offer equity in end of life care choices (NEoLCIN 2014). This is a complex issue, involving willingness to advance care plan, changing priorities as health deteriorates, and the human element of loneliness. More people, of a greater age, will live in single-person households in the future, and are likely to die alone. (housinglin.org.uk, 2012). Is this a service that is before its time? Statistics show that patients in areas of greater deprivation are less likely to die at home - thus should such a service be located by demographic need?

\section{P-165 VOLUNTEER CARE NAVIGATORS: ENRICHING PATIENT NETWORKS}

Vicky Lachenicht, Toni Hiscocks. Hospiscare, Exeter, UK

10.1136/bmjspcare-2016-001245.187

Background The hospice's strategic model of care review in 2014 found that patients wanted sustained face-to-face contact from their clinical nurse specialist. This is expensive so we developed the volunteer care navigator role. These are trained volunteers who develop trusting relationships with patients and their families, offer sustained emotional and practical support; signpost to relevant agencies and help with navigating the local health and social care system. The project was supported by a grant from the St James's Place Foundation.

Aims

- To care for more people at home, giving the hospice's palliative care nurse specialists more time to support more complex needs

- To support more people to access and benefit from local statutory or voluntary services

- To develop a new high-level volunteer model that can be shared and replicated.

Our approach

- Volunteering Manager recruited and trained a team of volunteer care navigators (25 as at 1 June 2016)

- Appointed an Assistant Practitioner to co-ordinate the service

- Developed comprehensive training programme for the volunteers
- Ensured the volunteer team were integrated with the hospice's community palliative care team

- Supported the volunteers through regular supervision sessions.

Outcomes

- 51 patient referrals, 1512 volunteering hours (nine months' data)

- Map developed and shared of local community agencies and activities

- Project shared with Association of Volunteer Managers.

Impact

- Improved emotional and practical support evidenced by patient and carer feedback

- Enriched patient networks evidenced by mapping

- Clinical nurse specialists' value enhanced support for patients that enables them to focus on more complex patients.

Learning

- Important service is integrated/co-located with the hospice's community palliative care nursing team

- Value of regular volunteer peer learning, support and sharing local knowledge

- Value of initial and continuing training

- Important to include dementia awareness in training.

\section{P-166 EMPOWERING VOLUNTEERS TO SUPPORT CARERS AND PATIENTS AT THE END OF LIFE}

Patricia Hamilton, Kevin Chesters. Douglas Macmillan Hospice, Stoke on Trent, UK

10.1136/bmjspcare-2016-001245.188

Background An End of Life Support Service set up in 2014 as a pilot project funded by Staffordshire County Council, was developed, to engage and assess the needs of carers. A service was developed providing: information, advice and volunteer support. The volunteers provide emotional and practical support to help end of life carers cope with demands and difficulties they faced.

Development The Carers Support Service proved to be a great success, reviews and feedback regularly sought from carers, patients, medical staff and volunteers, showed the support assisted in helping carers continue in their caring role as well as enabling the patient to remain at home.

Funding ended in 2015, the hospice used the learning from this project to inform the ongoing development of its services.

The hospice decided to develop this into a new service including those patients in need of additional home support, the service has now become Carer \& Patient Support Service.

One full time co-ordinator organises a team of volunteers to visit carers and patients known to the hospice in their own homes.

Volunteers Volunteers all received training et al., communication and listening, boundaries, confidentiality, safeguarding, and endof-life care, ongoing training and qualifications are offered.

Outcomes Carers report that they feel more able to cope, less isolated, their sense of well-being increased, more able to sustain their caring role.

Patients report that they feel less of a burden, knowing someone is visiting just for them, giving their carer a break, and when 